\title{
GESTAÇÃO EM PORTADORAS DE ANEMIA FALCIFORME: UM REVISÃO INTEGRATIVA
}

PREGNANCY IN WOMEN WITH SICKLE CELL ANEMIA: AN INTEGRATIVE REVIEW

\author{
Adiane Leal Lima ${ }^{a^{*}}$, Ivonildes da Hora Santana ${ }^{b^{*}}$, \\ Técia Maria Santos Carneiro e Cordeiro ${ }^{* *}$, Magno Conceição das Merces ${ }^{\mathrm{d}^{* *}}$, \\ Fernanda de Oliveira Souza ${ }^{{ }^{* * *}}$, Maria das Graças Santos Oliveira ${ }^{*}$ \\ aivonildes_hs2011@hotmail.com, bivonildes_hs2011@hotmail.com, cteciamarya@yahoo.com.br, \\ dmagnomerces@hotmail.com, enandaolisouza@gmail.com, fgracavieira1953@hotmail.com \\ *Faculdade Santo Antônio - Alagoinhas (BA), Brasil. \\ **Universidade Federal da Bahia - Salvador (BA), Brasil \\ ***Universidade Estadual de Feira de Santana - Feira de Santana (BA), Brasil
}

Data de recebimento do artigo: 21/01/2017

Data de aceite do artigo: 25/04/2017

\section{RESUMO}

Objetivo: Analisar as produçôes científicas brasileiras acerca da gestação em portadoras de anemia falciforme. Método: É um estudo de revisão integrativa realizada na base de dados da Biblioteca Virtual de Saúde (BVS), com o uso dos descritores gravidez e anemia falciforme, no período de 2006 a 2015. Resultados: As publicaçóes se concentraram na região Sudeste do Brasil em que o número de casos é menor que nas demais regiōes. Os fatores gestacionais complicadores na Anemia Falciforme (AF) foram anemias, infecçôes, trabalho de parto prematuro, gravidez na adolescência, entre outros. E os fatores que aumentam os riscos maternos e fetais foi o aborto espontâneo, a ruptura precoce de membranas, o crescimento intrauterino restrito, infecção pós-parto, entre outros. Conclusão: É necessário que as gestantes portadoras de anemia falciforme sejam acompanhadas por uma equipe multiprofissional referência em gestação de alto risco, o hematologista e a equipe da atenção básica à saúde visando à atenção integral e a diminuição e/ou controle riscos maternos e fetais.

Palavras-chave: Enfermagem. Fatores de Risco. Anemia Falciforme. Gravidez.

\section{ABSTRACT}

Objective: To analyze Brazilian scientific productions about gestation in patients with sickle cell anemia. Method: It is an integrative review study carried out in the Virtual Health Library (VHL) database, using the descriptors pregnancy and sickle cell anemia, in the periodical from 2006 to 2015. Results: The publications focused on the Southeast region of Brazil, where the number of cases is lower than in other regions. The complicating gestational factors in sickle cell anemia were anemia, infections, preterm labor, teenage pregnancy, among others. And factors that increased maternal and fetal risks were spontaneous abortion, early rupture of membranes, restricted intrauterine growth, postpartum infection, among others. Conclusion: It is necessary that the pregnant women with sickle cell anemia be accompanied by a multiprofessional reference group in high risk pregnancy, the hematologist and the primary health care team aiming at integral care and the reduction and / or control of maternal and fetal risks.

Keywords: Nursing. Risk Factors. Anemia, Sickle Cell. Pregnancy. 


\section{Introdução}

A anemia falciforme (AF) é uma doença que causa a deformidade estrutural da hemoglobina. Umas das doenças hereditárias mais comuns do Brasil, pelas características dos brasileiros, se destacam por alteraçóes genéticas que determinam a substituição das bases nitrogenadas Timina (T) por Adenina (A) causando a substituiçáo do aminoácido Glutâmico por Valina na posição seis da cadeia Beta da hemoglobina ${ }^{1}$.

Esta mudança na estrutura determina uma alteração no formato e na função da hemoglobina o que causa distorção dos eritrócitos, se formando como uma "foice", assim a hemoglobina apresentará meia vida (hemólise) por isso provocará um quadro de anemia crôni$\mathrm{ca}^{2}$. Baseado neste quadro as pessoas portadoras desta doença necessitam de cuidados de saúde especializados e acompanhamento para evitar complicaçôes.

Estima-se que no Brasil 6 a $10 \%$ da população de raça/cor da pele preta e parda tenha o traço falciforme e $2 \%$ em toda a população, esta proporção está relacionada à miscigenação do país e a origem da própria doença - africana. Entre as regióes se concentra no Norte e Nordeste com uma prevalência de 6 a 10\%, enquanto nas regióes Sul e Sudeste 2 a 3\%. A Bahia é um dos estados que apresenta maior incidência da anemia falciforme e do traço falciforme sendo 1:650 nascidos vivos com a $\mathrm{AF}$ e 1:17 nascidos vivos com o traço falciforme ${ }^{3,4}$. A Organização Mundial de Saúde estima 500.000 nascimentos de mulheres com AF por ano5.

Por a AF se tratar de uma doença pouco conheci$\mathrm{da}$ às pessoas não ficam atentas aos fatores hereditários e sintomas apresentados para fazer o rastreamento e diagnosticar a patologia precocemente. Além disso, as mulheres que pretendem engravidar é preciso rastrear no planejamento familiar a fim de facilitar a pré-concepção para conseguir uma gestação sem complicaçôes extremas ${ }^{6}$.

As gestantes com a AF apresentam geralmente insegurança e desconhecimento como agir durante esta fase da vida, assim como a maioria não estão preparadas para enfrentar a dimensão clínica da doença, outro problema é se o companheiro não tem a doença, pois dificulta a compreensão do mesmo sobre a patologia, suas consequências na gestação e as possíveis limitaçóes ${ }^{6}$.

Sendo assim, o presente estudo justifica-se pela necessidade existente de buscar as evidencias científicas publicadas sobre gestação em portadoras de Anemia Falciforme a fim de contribuir para ampliar o conhecimento cientifico na área das ciências de saúde e colaborar para a atuação eficiente dos profissionais de saúde, entre eles os enfermeiros. Desta forma, objetivou-se analisar as produções científicas brasileiras acerca da gestação em portadoras de anemia falciforme.

\section{Métodos}

Trata-se de um estudo de revisáo integrativa de ampla abordagem metodológica referente às revisóes, inclui vários tipos de pesquisas, combina dados da bibliografia teórica, além de incorporar definiçóes de conceitos, revisão de teóricos de evidências e análise de problemas metodológicos de um tópico particular que gera um panorama consistente e comparativo de assuntos relevantes ${ }^{7}$.

A revisão integrativa é constituída de seis fases, as quais delinearam este estudo. Elaborou-se a pergunta problema: Qual o conhecimento disponível na base de dados da Biblioteca Virtual de Saúde (BVS) acerca da Gestação na portadora de Anemia Falciforme?

A busca das produçóes científicas foi realizada na base de dados da BVS com o uso dos Descritores em Ciências da Saúde (DeCS) com a seguinte combinação: gravidez $A N D$ anemia falciforme no "titulo, resumo, assunto". Para a seleção utilizou-se os critérios de inclusão: a) artigos publicados em texto completo; b) artigos publicados no período de 2006 a 2015; c) artigos indexados no idioma português e espanhol; d) com abordagem em Gestação na Anemia Falciforme. Dessa forma, o corpus documental deste trabalho é constituído de seis artigos científicos.

Os dados foram coletados por meio de um instrumento elaborado pelas autoras contendo: título, ano, periódico, autores, objetivos, principais resultados e conclusóes (Quadro 1).

Para análise dos artigos incluídos no corpus documental deste estudo foi utilizada a abordagem qualitativa exploratória a fim de evidenciar o contexto que tem sido analisado acerca do objeto em estudo - gestação em portadoras de anemia falciforme.

Foram realizadas as discussóes dos principais achados e a exposição da revisão integrativa propriamente dita. Os dados foram analisados e discutidos segundo a análise de conteúdo de Bardin (1970) por meio das seguintes etapas: pré-análise, exploração dos materiais e tratamento dos resultados e interpretação dos dados, emergindo três categorias temáticas, a saber: 1) Característica das Produçôes Cientifica; 2) Fatores gestacionais complicadores da Anemia Falciforme; 3) Gestaçáo em portadoras de Anemia Falciforme e os riscos maternos fetais.

\section{Resultados e discussão}

\section{Características das produções científicas}

Foram encontrados 1.152 artigos na base de dados BVS, após a aplicação dos critérios de inclusão e a leitura do título, resumo e artigo completo selecionou-se 
Quadro 1 - Corpus documental acerca da Gestação em portadora de Anemia Falciforme, 2006 a 2015.

\begin{tabular}{|c|c|c|c|c|c|}
\hline Título/Ano & Periódico & Autores & Objetivos & Principais Resultados & Conclusão \\
\hline $\begin{array}{l}\text { Gravidez e } \\
\text { contracepção } \\
\text { na doença } \\
\text { falciforme } / 2007^{8}\end{array}$ & $\begin{array}{l}\text { Revista Brasileira } \\
\text { de hematologia e } \\
\text { Hemoterapia. }\end{array}$ & Zanette AMD. & $\begin{array}{l}\text { Abordar os principais } \\
\text { aspectos relacionados } \\
\text { à contracepção e à } \\
\text { gestação em pacientes } \\
\text { com anemia falciforme. }\end{array}$ & $\begin{array}{l}\text { A indicação de método } \\
\text { contraceptivo hormonal } \\
\text { de primeira escolha } \\
\text { para mulheres com } \\
\text { anemia falciforme é a } \\
\text { Medroxiprogesterona visando } \\
\text { proporcionar á paciente uma } \\
\text { contracepção prática, segura e } \\
\text { bem tolerada. }\end{array}$ & $\begin{array}{l}\text { Visando a redução da } \\
\text { morbidade e mortalidade } \\
\text { fetais e maternas e } \\
\text { complicaçóes em } \\
\text { gestante com anemia } \\
\text { falciforme é importante } \\
\text { que essas mulheres sejam } \\
\text { acompanhadas por médico } \\
\text { e equipe multidisciplinares } \\
\text { na contracepçáo hormonal } \\
\text { e em qualquer método que } \\
\text { for escolhido. }\end{array}$ \\
\hline
\end{tabular}

Resultados maternos e perinatais em gestaçóes complicadas por doenças falciformes $/ 2010^{\circ}$

Revista Brasileira de Ginecologia e Obstetrícia
Nomura RMY, Igai AMK, Tosta K,

Fonseca GHH, Gualandro SFM, Zugaib M.
Analisar as complicaçóes maternas e os resultados perinatais nas pacientes portadoras de doenças falciformes, comparando as com as gestantes portadoras de traço falciforme que foram acompanhadas no pré-natal e no parto em hospital universitário.
As complicaçôes verificadas foram internação antes do parto, ocorrência de infecçáo urinária, pneumonia, hipertensão pulmonar e restrição do crescimento fetal.
A gravidez impóe alteraçóes importantes no organismo, levando em conta maior incidência de complicaçóes que necessitam de maiores cuidados para minimizá-los ou combatê-las.

A mortalidade materna

$\begin{array}{ll}\text { As intercorrências que } & \text { e fetal está diretamente } \\ \text { poderão ocorrer são: síndrome } & \text { relacionada às complicaçooes }\end{array}$ torácica aguda, trombose da anemia falciforme. cerebral, pielonefrite, trabalho Portanto a gravidez de parto pré-termo, ruptura associa-se com riscos prematura de membranas, de complicaçóes que descolamento de placenta, sangramento anteparto e outras complicaçôes.

necessitam de cuidados com orientaçáo correta e
Discutir as principais complicaçóes que podem levar a situaçôe de urgência durante a gestação da paciente com anemia falciforme. com doença

Revista Médica

Barros NN,

Macedo RSPB,

Cruz SG et al. imediatos e são minimizados cuidados médicos precoces.

Dentre os três trimestres de gestação notou-se que a gestante foi submetida à transfusão sanguínea, e não houve melhora da

Gravidez na adolescência e sua interação com anemia falciforme $/ 2012^{11}$

Revista Médica de Barbosa CG, Minas Geraica de Dias LRQ Abreu MTCL.
Relatar as complicaçóes maternas ocorridas na gravidez de adolescentes de 16 anos com anemia falciforme. anemia, mas que o feto se manteve saudável. As transfusōes realizadas $n$ paciente durante o período gestacional ocorreram visando melhorar a anemia, entretanto, o acúmulo de ferro no organismo elevou os resultados de ferritina e ferro sérico.

A partir do momento que a mulher tem conhecimento da sua patologia passa a compreender os riscos que as complicaçốes da doença podem causar durante $o$ período gestacional.

No decorrer do estudo fo observado o quantitativo de indagaçóes a cerca da gravidez na portadora de anemia falciforme, a mulher questiona sua capacidade de cuidar dessa criança e amá-la.
O enfrentamento da situação gravidez na adolescência e anemia falciforme é importante e deve ser explorada para que a adolescente e sua família entendam como agir em sua necessidade possibilitando a redução da mortalidade fetal e materna.

O estudo aponta a carência que ainda há de informaçôe acerca de esclarecimentos para essa população, planejamento préconcepcional e a percepçáo do autocuidado para uma gravidez tranquila.

Percebe-se que as mães portadoras de anemia falciforme têm muitas preocupaçóes a cercada gestação, se seu bebê vai herdar a doença, se ela vai ter disponibilidade para exercer a maternidade. 
seis artigos, sendo estes que fazem parte do corpus documental deste estudo.

Esses artigos foram publicados em igual proporção de 2006 a $2010(\mathrm{~N}=3)$ e 2011 a $2014(\mathrm{~N}=3)$ e todos foram escritos por profissionais da área da saúde. Percebe-se a necessidade de maiores investimentos em pesquisas acerca desta temática relevante para garantia da saúde das mulheres portadoras de anemia falciforme.

As abordagens metodológicas usadas nos artigos foram à qualitativa e a quantitativa numa mesma proporção, onde apontam o interesse de avaliar tantos as percepçóes dos sujeitos e os pensamentos de diferentes autores, quanto à forma de abordar a problematização.

Os artigos foram publicados nos estados da Bahia, Rio de Janeiro, São Paulo e Minas Gerais em periódicos da área da saúde. A regiāo Sudeste é uma das regiōes que apresentam menores taxas de prevalência da anemia falciforme e a que mais publicou nestes últimos 10 anos, assim se faz necessário uma maior atenção pelos pesquisadores das regióes Nordeste e Norte que apresentaram pouca e nenhuma publicaçáo, respectivamente e são as regióes que apresentam o maior número de casos.

\section{Fatores gestacionais complicadores da anemia falciforme}

Os estudos apontam diversos fatores gestacionais complicadores como mortalidade materna, anemias, infecçôes, trabalho de parto prematuro, gravidez na adolescência, os quais estão relacionados às complicações da própria AF (Figura 1).

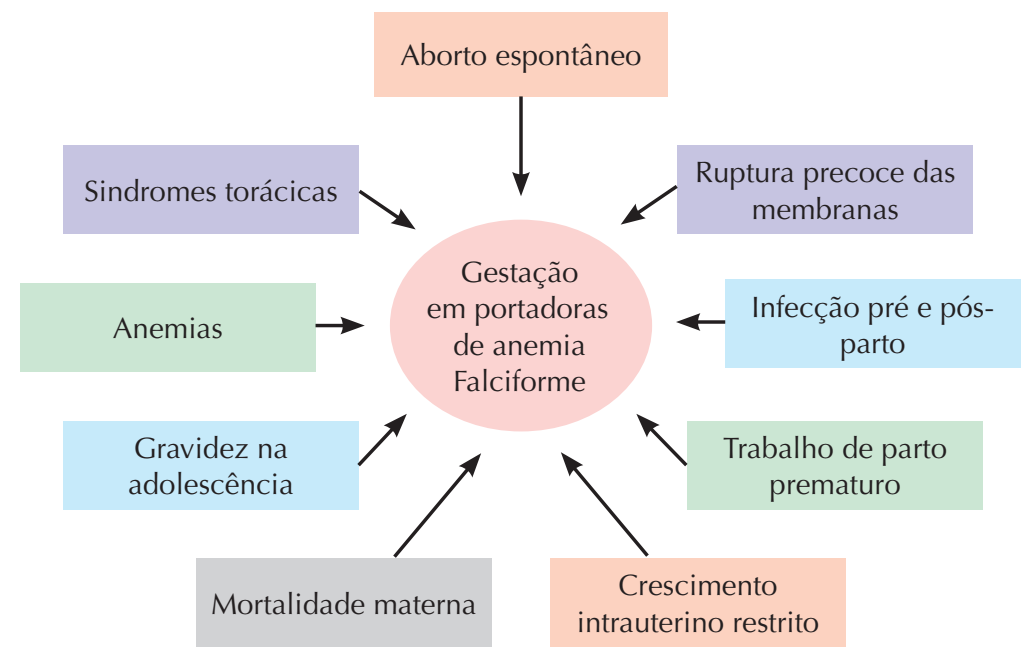

Figura 1: Fatores complicadores e riscos maternos e fetais na gestação em portadoras de anemia falciforme.

A gestação em portadora de anemia falciforme torna-se potencial agravante para a saúde da mulher e do concepto e pode deixá-la preocupada e insegura 5 . Mesmo assim, sonham em realizar o desejo da maternidade, sendo necessária uma assistência multiprofissional durante o período que compreende o parto e puerpério, momento de grande felicidade, porém crucial pelo risco de morte ou de nascer com a anemia falciforme ${ }^{12}$.

Desde a década de 1972, as taxas de mortalidade materna e perinatal entre gestantes portadoras de anemia falciforme foram muito elevadas. Antes eram fornecidas informaçóes para as mulheres com esta patologia a abster-se de engravidar ou realizar laqueadura tubária, mesmo antes de engravidar ou pós-primeira gravidez e abortos. Com os avanços na medicina desde a década de 1980 foi observada melhoras significativas na assistência ajudando no prognóstico dessas mulheres e na possibilidade delas engravidarem?.

Vários são os fatores que podem complicar a gestação das mulheres portadoras de anemia falciforme por causa da falcização das hemácias, as principais são: hipóxia, alteraçôes no conteúdo iônico das hemácias, desidratação, concentração intracelular de hemoglobina ${ }^{10}$. A síndrome torácica aguda, infecções, anemia severa, colecistite, hiperesplenismo, entre outras, são intercorrências que precisam ser minuciosamente avaliadas, detectadas e tratadas, uma das susceptibilidades é o parto prematuro acometendo aproximadamente $30 \%$ a $50 \%$ das mulheres antes de completar 36 semanas, sendo que a média é, geralmente, de 34 semanas de gravidez, onde esse parto poderá ser natural ou cesáreo de acordo com a necessidade da paciente ${ }^{8}$. 
A crise dolorosa é a causa mais comum de morbidade entre outros fatores como infecção pré e pós-parto especialmente pielonefrite e as pneumonias, agravo da anemia, restriçáo do crescimento fetal, parto prematuro, natimorto, aborto espontâneo, agravamento das lesóes ósseas e da retinopatia, baixo peso ao nascer e pré-eclâmpsia. No terceiro trimestre de gestação é muito comum que ocorram essas complicaçôes, tanto para portadoras de anemia falciforme quanto para aquelas com o traço falciforme ${ }^{8,9}$.

Porém, esses agravos acontecem com frequência no caso da junção com a gravidez na adolescência, necessitando de cuidados especiais devido à destruição precoce dos eritrócitos pelo baço, sendo que a medula óssea não consegue repor essas células causando anemia hemolítica crônica. Os episódios de oclusão vascular recorrentes provocam desconforto para a mãe e restrição do desenvolvimento fetal ${ }^{11}$. As hemácias com seu formato em foice causam vasoclusão e diminui a condução de oxigênio e nutrientes para a placenta deixando de suprir as necessidades do concepto, com isso expondo a mulher portadora da anemia falciforme ao risco de abortamento e morte neonatal ${ }^{8,11}$.

Nesse caso o pré-natal da portadora de anemia falciforme deverá ter observaçóes específicas para a detecção precoce dos fatores agravantes além dos cuidados com a suplementação vitamínica, orientar quanto à ingesta hídrica, evitar exposição ao sol e ao frio além de atividades físicas exaustivas para não correr o risco de desidratar?

Os achados desta revisão apontam que o aborto espontâneo, o trabalho de parto prematuro, a ruptura precoce de membranas, as infecçôes pós-parto e o crescimento intrauterino restrito são fatores que contribuem para maiores riscos maternos e fetais (Figura 1).

\section{Gestação em portadoras de Anemia Falciforme e os riscos maternos fetais}

Devido aos riscos fetais a gravidez na AF é considerada de alto risco sendo necessário o acompanhamento do pré-natal minucioso por equipe especializada ${ }^{10}$. Além do acompanhamento imediato no pré-natal de alto risco juntamente com apoio psicológico e a presença da família, a qual precisa estar capacitada para dar apoio a esta mulher em um momento táo importante quanto o da maternidade ${ }^{12}$.

A interação materna fetal necessita de rastreamento por meio de ultrassonografia obstétrica e exames para que possa ter controle do fluxo sanguíneo que está sendo filtrado para a placenta. Para pacientes homozigoto $\mathrm{HbSS}$ os riscos de complicaçóes fetais são maiores se comparadas a heterozigoto HbAA, que pode ocorrer aborto espontâneo, trabalho de parto pré-maturo, ruptura precoce das membranas e infecção pós-parto ${ }^{10}$.
Estes agravos podem ocasionar em riscos ao feto como baixo desenvolvimento fetal que pode agravar o funcionamento dos órgãos deste concepto após o nascimento.

Outros riscos são o crescimento intrauterino restrito e o baixo peso ao nascer que ocorre, geralmente, devido ao comprometimento da circulação materna e placentária ocasionada pela vasoclusão, a qual diminui a irrigação sanguínea da placenta aumentando complicaçôes que poderão afetar o concepto acelerando o processo do parto, o que agrava a situação de saúde do concepto ${ }^{9,10}$.

Para evitar a morte da gestante e de seu concepto com anemia falciforme a interação entre profissionais obstetra e hematologista ${ }^{5}$ é extremamente indispensável por proporcionar qualidade de vida oferecendo tratamento intensivo evitando que a gestante sofra com dor torácica aguda e insuficiência respiratória o que afeta diretamente seu feto9. Embora ainda seja inexistente uma equipe composta com especialistas para prestar a atenção à saúde pertinente à mulher com $\mathrm{AF}$.

As representaçóes maternas durante o planejamento familiar, gestação, parto e puerpério é afetada pela $\mathrm{AF}$, o que pode gerar medos, angústias, fantasias a respeito da futura mãe e de seu bebê, sendo assim, torna-se relevante também a observação destas representaçóes como ferramenta indispensável para prevenção dos distúrbios de relação entre o binômio - mãe e bebê $\hat{~}^{\text {. }}$

\section{Conclusão}

As produçóes científicas brasileiras acerca da gestação em portadoras de anemia falciforme ainda merecem atenção por parte dos pesquisadores, por se tratar de uma patologia que determina fatores complicadores durante a gestação gerando riscos para gestante e para o feto. Os principais fatores complicadores da gestação foram associados ao desenvolvimento da sintomatologia da anemia falciforme, entre eles a gravidez na adolescência, as anemias, infecçōes pré e pós-parto, trabalho de parto prematuro, mortalidade materna, assim como os fatores que aumentam os riscos maternos e fetais: o aborto espontâneo, a ruptura precoce de membranas, o crescimento intrauterino restrito e a infecção pós-parto, $\mathrm{e}$ as representaçóes maternas que influenciam no estabelecimento de vínculo entre o binômio.

Percebeu-se que, mesmo com os avanços alcançados na área da saúde, ainda são incipientes publicaçôes acerca da $\mathrm{AF}$ em gestantes e a atenção segura e protetora para que a portadora de anemia falciforme possa engravidar sem medos e anseios das complicaçóes que podem ocasionar neste período. Sendo assim, se faz necessária que as gestantes portadoras de anemia falciforme sejam acompanhadas por uma equipe multiprofissional referência em gestação de alto risco, o hematologista e a equipe da 
atenção básica à saúde visando à atenção integral e a diminuição e/ou controle dos riscos maternos e fetais.

Assim sendo, propóe-se futuros investimentos em estudos nesta área da gestação de alto risco a fim de identificar a associação entre facilidades de acesso aos serviços especializados de saúde e a ocorrência de complicaçóes maternas e fetais na gestação em portadoras de anemia falciforme. E com isso contribuir para que gestores da saúde possam avaliar as açóes estabelecidas a esta população.

\section{Referências}

1. Galiza Neto GC, Pitombeira MS. Aspectos Moleculares da Anemia Falciforme. J Bras Patol Med Lab. 2003; 39 (1): 51-6.

2. Brasil. Agencia Nacional de Vigilância Sanitária. Manual de Educação em Saúde Auto cuidado na Doença Falciforme. Brasília-DF: Ministério da Saúde; 2008.

3. Brasil. Agencia Nacional de Vigilância Sanitária. Doença Falciforme Condutas Básicas para tratamento. Brasília-DF: Ministério da Saúde; 2012.

4. Brasil. Atenção integral a saúde das mulheres. Brasília-DF: Ministério da Saúde; 2015.
5. Cox FEM, Beauquier-Maccotta B. Representaçóes maternas durante uma gravidez patológica: o caso da anemia facilforme. Estilos clin. 2014; 19 (2): 309-24.

6. Araújo PIC. O autocuidado na doença falciforme. Rev Bras Hematol Hemoter. 2007; 29 (3): 239-6.

7. Souza MT, Silva MD, Carvalho R. Revisão integrativa: o que é e como fazer. Einstein. 2010; 8 (1pt 1): 102-6

8. Zanette AMD. Gravidez e contracepção na doença falciforme. Rev Bras Hematol Hemoter. 2007; 29 (3): 309-12.

9. Nomura RMY, Igai AMK, Tosta K, Fonseca GHH, Guanlandro SFM, Zugaib M. Resultados maternos e perinatais em gestaçóes complicadas por doenças falciformes. Rev Bras Ginecol Obstet. 2010; 32 (8): 405-11.

10. Monken FV, Barros NN, Valadares PJC, Macedo RSPB, Cruz SG, Cury PS et al. Situaçôes de emergência na gestante com doença falciforme. Rev Med Minas Gerais 2010; 20 (2 Supl 1 ): S73-S77.

11. Barbosa CG, Dias LRQ, Abreu MTCL. Gravidez na adolescência e suas interaçốes com anemia falciforme. Rev Med Minas Gerais 2012; 22 (2): 231-4.

12. Xavier ASG, Ferreira SL, Carvalho ESS, Araújo EM, Cordeiro RC. Percepción de mujeres con anemia falciforme sobre la gestación: estudio exploratório. Online Braz J Nurs. 2013; 12 (4): 834-43.

\section{Como citar este artigo:}

Lima AL, Santana IH, Cordeiro TMSC, Merces MC, Souza FO, Oliveira MGS. Gestação em portadoras de anemia falciforme: uma revisão integrativa. Rev. Aten. Saúde. 2017;15(52):66-71. 